\title{
Adsorption Studies of Nitrate by Geo-Physical Environment (Laterite soil) of the Study Area Bidar Urban \& its Industrial Area, Karnataka State, India
}

\author{
Shivasharanappa ${ }^{1, *}$, Padaki Srinivas ${ }^{2}$, Srinivas Kushtagi $i^{1}$ \\ ${ }^{1}$ Department of Civil Engineering, P. D. A. College of Engineering (Autonomous Institution), \\ Gulbarga - 585102, Karnataka State, India \\ ${ }^{2}$ Department of Chemistry, P. D. A. College of Engineering (Autonomous Institution), \\ Gulbarga - 585102, Karnataka State, India \\ *Email: shivasharanappa.g@gmail.com
}

\begin{abstract}
In the present work, adsorption of Nitrate on Laterite soil has been studied using batch adsorption techniques. Main objectives of this study is to study the physical properties of Laterite soil, detection of Nitrate removal by adsorbent Laterite soil as a function of contact time, adsorbent dosage, $\mathrm{pH}$, to study sorption kinetics, and to study isothermal pattern. The results of this study showed that the Optimum contact time, Optimum dosage and Optimum $\mathrm{pH}$ for adsorption of Nitrate on Laterite soil reached to equilibrium after 130 minutes, with removal efficiency of $68 \%, 1400 \mathrm{mg}$ as optimum dosage and at optimum $\mathrm{pH}$ of 6 . The rate of adsorption of Nitrate obeys first order rate equation. The obtained results of the batch experiments are best fitted to Langmuir and Freundlich adsorption isotherms. From the experimental analysis it is concluded that Laterite soil shows good removal efficiency and hence can be used as adsorbent.
\end{abstract}

Keywords: Nitrate Adsorption; Laterite; Batch Experiments; Freundlich Isotherm; Langmuir Isotherm

\section{INTRODUCTION}

For the first time in this entire cultural history, man is facing one of the most horrible ecological crises - the problem of pollution of his environment, which in the past was pure, virgin, undisturbed, uncontaminated, and basically quite hospitable for him [6]. Waste disposal from various industries, municipal dumping in the urban areas and increased use of chemical fertilizers, pesticides and irrigation water are of great environmental concern .The residues of fertilizers, pesticides and irrigation water on one hand, increased agricultural production on the other hand, created adverse impact on soil and water bodies [6]. Of the many causes of pollution including sewage and fertilizers, contain nutrients such as Nitrogen/Phosphorous. In excess levels, nutrients over stimulate the growth of aquatic plants and algae. Waterborne chemical pollution entering rivers and streams cause tremendous amounts of destruction and in turn the ground water too gets contaminated. Animal wastes are high in oxygen demanding, contain nitrogen and phosphorus, and they often harbor pathogenic organisms. Wastes from commercial feeders are stored and disposed of on land.

Their main threat is to natural waters, and therefore, is from runoff and leaching [4]. 
The high doses of nitrogenous/phosphorous fertilizer applied to soil immediately followed by heavy rainfall causes some nitrogen losses through volatilization and leaching processes [2]. Thus once ecosystems are contaminated by these elements, they become potential threat for many years. Their accumulation reduces soil fertility, soil microbial activity, plant growth, and the quality of agricultural products [6]. It is observed that when an element is applied to soil, some of it may leach and join ground water table, some may be retained by the soil particles, some may be lost from the soil other than leaching loss, some may be incorporated by soil microorganisms or some may be taken up by plant. In most cases, several contaminants are simultaneously released into the environment. Therefore, it is of crucial importance to study in detail the mutual influence of the different minerals in soil retention process. Soil has an important role in Nitrogen/Phosphate accumulation, retarding the migration process, which influences further ground and surface water contamination process $[3,5,7]$.

The study Area Bidar urban is the headquarters of the Bidar district of Karnataka, which is located in the northern maidan region of the state occupying the northern most part of Karnataka State. It is situated at a distance of $669 \mathrm{Kms}$. from the state capital Bangalore and at a distance of $141 \mathrm{Kms}$ from Hyderabad, Andhra Pradesh state. Ground water quality of Bidar urban \& its industrial area (Total 35 wards, 3 samples in each ward) are analyzed for physico-chemical including heavy metals and biological characteristics during the years 2009, 2010 \& 2011 (Pre-monsoon and Post-monsoon), revealed less pollution. Correlation and regression, Hydro-geochemical, Water Quality Index (WQI) \& Factor analysis are worked out on the above analyzed data also proved less pollution. Objective of the present work is to study geo-physical environment of the existing soil (Laterite) in the study area, adsorption studies on laterite soil by taking known concentrations of nitrate was studied. The Bidar urban map and location are presented in Figures 1-2.

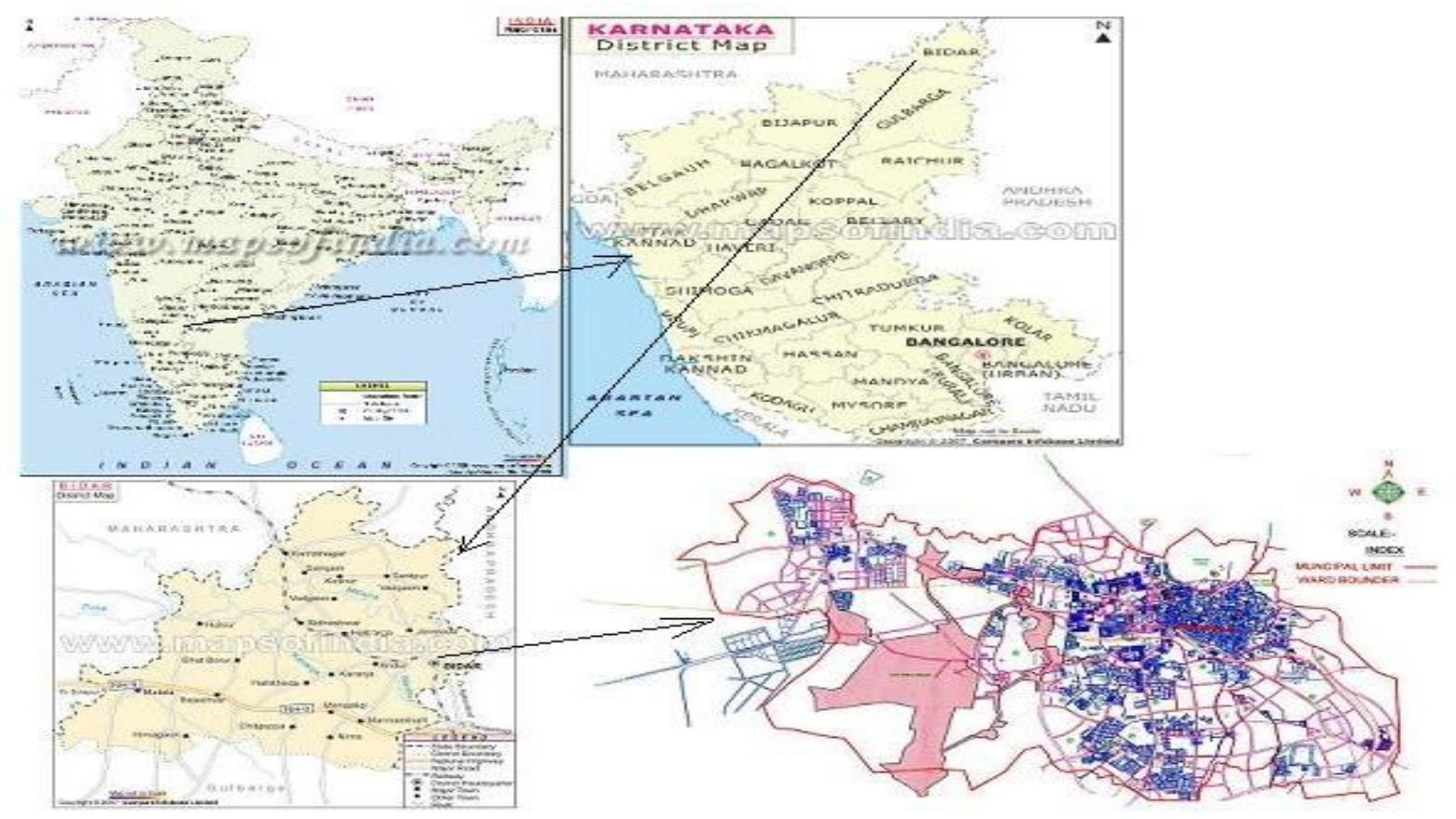

Figure 1. Showing the Location of Bidar Urban. 


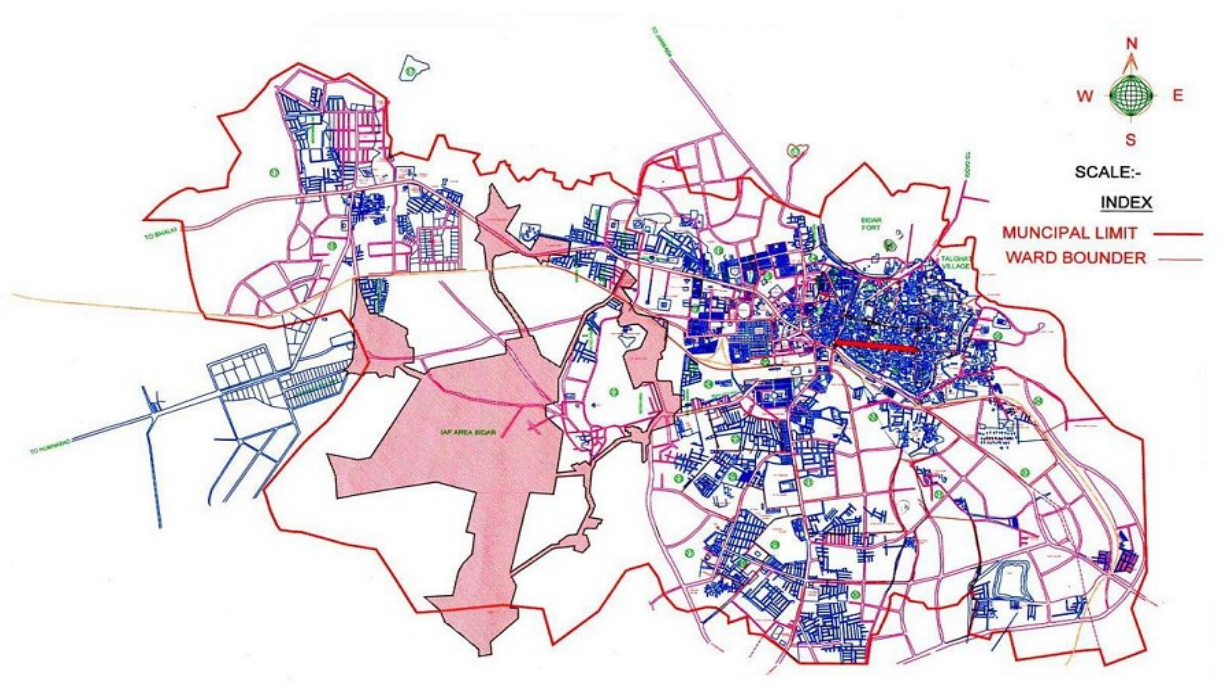

Figure 2. Bidar Urban Map.

\section{MATERIALS AND METHODS}

Soil samples of laterite were collected from different locations of Bidar urban, as they are locally available in entire Bidar district.

\section{1. Soil Studied}

Laterites are rich in iron and aluminium, formed in hot and wet tropical areas. Nearly all laterite soils are rusty-red because of iron oxides. They develop by intensive and long-lasting weathering of the underlying parent rock. Tropical weathering (laterization) is a prolonged process of mechanical and chemical weathering which produces a wide variety in the thickness, grade, chemistry, ore mineralogy and hard. Historically, laterite was cut into bricklike shapes as shown in Figure 3 and used in monument building. Since the mid-1970s trial sections of bituminous-surfaced low-volume roads have used laterite in place of stone as a base course. Thick laterite layers are porous and slightly permeable, so the layers can function as aquifers in rural areas. Locally available laterites are used in an acid solution, followed by precipitation to remove phosphorous and heavy metals at sewage treatment facilities.

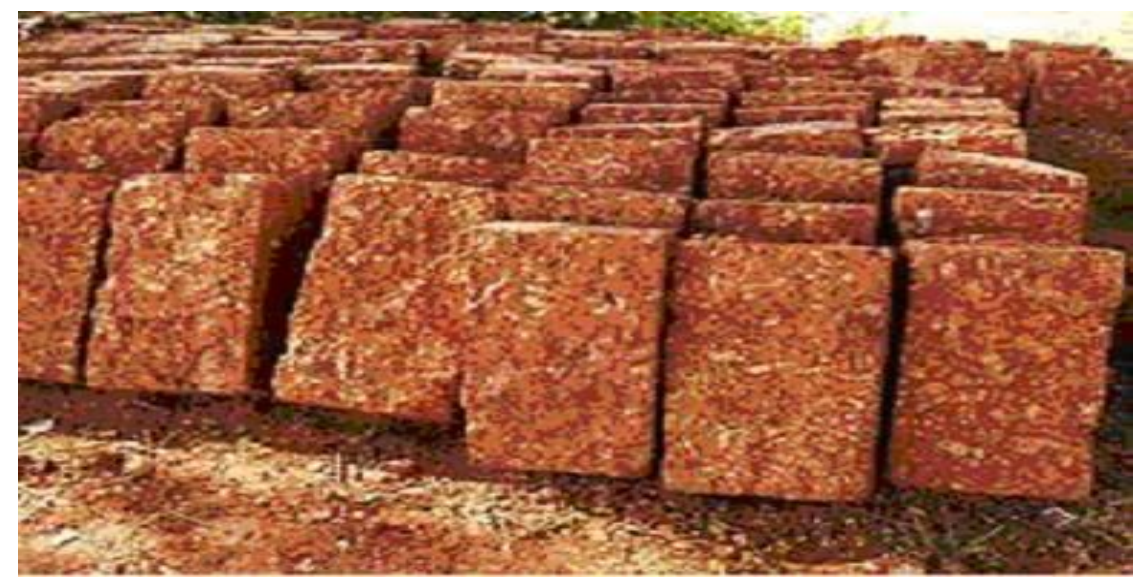

Figure 3. Laterite Soil. 
Instruments Used for Batch Sorption Studies: (1) Gyro shaker (2) Electronics Balance (3) Spectrophotometer (4) Titration Glass Wares.

\section{2. Soil Characterization}

The top soil of 10-20 cm was cleared and the samples of soil were collected by driving the cores into the soil. The samples were thoroughly washed in hot distilled water so as to remove all dirt and impurity, dried for one day, at $110{ }^{\circ} \mathrm{C}$ in an electric oven, followed by crushing and sieving, to obtain the particles by an average diameter of $150 \mu$. The final samples were dried, desiccated and preserved in air tight chamber for subsequent analysis and experiments were studied. The laterite soil thus collected from Bidar urban is analyzed for physical and chemical parameters. Moisture content, Decolorizing power, $\mathrm{pH}$, Surface area, Specific gravity, and Bulk density of the soil were determined and listed in Table 1.

Table 1. Main Soil Characteristics [1].

\begin{tabular}{|c|c|c|}
\hline SI. No & Characteristics & Laterite Soil Values \\
\hline 1 & Moisture content & $8.31 \%$ \\
\hline 2 & Decolorizing power & $14 \mathrm{mg} / 1$ \\
\hline 3 & $\mathrm{pH}$ & 8.3 \\
\hline 4 & Surface area & $550 \mathrm{mg} / \mathrm{m}^{2}$ \\
\hline 5 & Specific gravity & 2.083 \\
\hline 6 & Bulk density & $1.008 \mathrm{mg} / \mathrm{cm}^{2}$ \\
\hline
\end{tabular}

\section{3. Adsorption Isotherms}

Adsorption isotherms are developed by exposing a given amount of adsorbate in a fixed volume of liquid to varying amounts of adsorbate. Equations that are often used to describe the experimental isotherm data were developed by Freundlich \& Langmuir.

\section{3. 1 Freundlich Isotherm}

Freundlich isotherm is used most commonly to describe the adsorption characteristics, derived empirically in 1912.

The general form of Freundlich equation is,

$$
\mathrm{q}=(\mathrm{x} / \mathrm{m})=\mathrm{K} \mathrm{C}^{1 / \mathrm{n}}
$$

Where,

$(\mathrm{x} / \mathrm{m})=$ Amount of solute adsorbed per unit mass of adsorbent in $\mathrm{mg} / \mathrm{g}$ $\mathrm{C}=$ Equilibrium concentration of adsorbate in solution after adsorption in $\mathrm{mg} / \mathrm{L}$

$\mathrm{K}=$ Freundlich capacity factor

$(1 / \mathrm{n})=$ Freundlich intensity factor 
The constants ' $K$ ' and ' $n$ ' in the equation (1), can be evaluated by plotting amount of solute adsorbed per unit mass of adsorbent versus equilibrium concentration of adsorbate in solution after adsorption on a graph. The Freundlich equation is basically empirical but is often useful as means for data description. Data are usually fitted to the logarithmic form of equation.

$$
\log (\mathrm{x} / \mathrm{m})=\log \mathrm{K}+(1 / \mathrm{n}) \log \mathrm{C}
$$

A graph is plotted with $\log (\mathrm{x} / \mathrm{m})$ vs. $\log \mathrm{C}$, gives a straight line with slope as $(1 / \mathrm{n})$, and intercept value as $(\mathrm{x} / \mathrm{m})$, when $\mathrm{C}=1$. Smaller value of $1 / \mathrm{n}$ points out a better adsorption mechanism and formation of relatively stronger bond between adsorbate and adsorbent. If $(1 / n)<1$, bond energies with surface density, if $(1 / n)>1$, bond decreases with surface density and if $(1 / n)=1$ surface sites are open in order to generate the equilibrium data.

\section{3. 2 Langmuir Isotherm}

Langmuir isotherm is based on the assumption that point of valance exists on the surface of the adsorbent and that each of these site is capable of adsorbing one molecule. It is assumed that the adsorption sites have equal affinities for molecules of adsorbate and that the presence of adsorbed molecules at one site will not affect the adsorption of molecules at an adjacent site

The Langmuir equation is commonly written as

$$
\begin{aligned}
& \mathrm{q}=(\mathrm{x} / \mathrm{m})=(\mathrm{abC}) /(1+\mathrm{bC}) \\
& {[\mathrm{C} /(\mathrm{x} / \mathrm{m})]=(1 / \mathrm{ab})+(\mathrm{C} / \mathrm{a})}
\end{aligned}
$$

Where, $\mathrm{q}=$ Amount of solute adsorbed per unit mass of adsorbent in $\mathrm{mg} / \mathrm{g}, \mathrm{C}=$ Equilibrium concentration of adsorbate in solution after adsorption in $\mathrm{mg} / \mathrm{L}$ and ' $\mathrm{a}$ ' and ' $\mathrm{b}$ ' are Langmuir constants related to capacity and energy of adsorption respectively. Plot of ' $q$ ' vs. ' $C$ ' would give the value of constants. A dimensionless equilibrium parameter called separation factor, $\mathrm{R}$ is used to study the applicability of Langmuir adsorption isotherm. This is defined by Webber and Chakravarthi [10].

$$
\mathrm{R}=\left[1 /(1+\mathrm{a})^{*} \mathrm{C}_{0}\right]
$$

Where, $\mathrm{a}=$ Langmuir constant, $\mathrm{C}_{0}=$ initial concentration, $\mathrm{R}=$ Separation factor. From the above equation Webber and Chakravarthi given parameter indicating the shape of the isotherm are as shown in Table 2.

Table 2. Webber and Chakravarthi's parameter indicating the shape of the isotherm.

\begin{tabular}{|c|c|}
\hline Values of R & Type of Isotherm \\
\hline $\mathrm{R}>1$ & Unfavorable \\
\hline $\mathrm{R}=1$ & Linear \\
\hline $0<\mathrm{R}<1$ & Favorable \\
\hline $\mathrm{R}=0$ & Irreversible \\
\hline
\end{tabular}




\section{4. Determination of Nitrate [8]}

PDA (Phenol Disulphonic Acid) method from standard methods was adopted.

\section{RESULTS AND DISCUSSIONS}

A series of Batch experiments have been performed to determine the adsorption of nitrates on the laterite soil.

\section{1. Batch Sorption Experiments}

\section{1. 1. Effect of contact time}

Contact time has great influence on the adsorption process. The effects of contact time on the adsorption of nitrate on laterite soil were shown in Fig. 4. From the graph it is observed that the extent of nitrate adsorption increases with increase in time and attain equilibrium at particular time. The adsorption curve is characterized by sharp rise in initial stage and decrease near equilibrium. For the study of effect of contact time $100 \mathrm{~m} 1$ of $10 \mathrm{mg} / \mathrm{L} \mathrm{Nitrate}$ solution was mixed with $50 \mathrm{mg}$ of laterite soil sample and stirred for different period of contact time i.e., for $2 \mathrm{hr}$. and time interval varies as 3, 5, 10,20....160 min. For the selected interval of time, the solution taken from gyroshaker and is filtered and analyzed for Nitrate concentration using spectrophotometer. From the graph after equilibrium further increase in time, adsorption is not changing hence the optimum contact time for laterite soil is 130 mins.

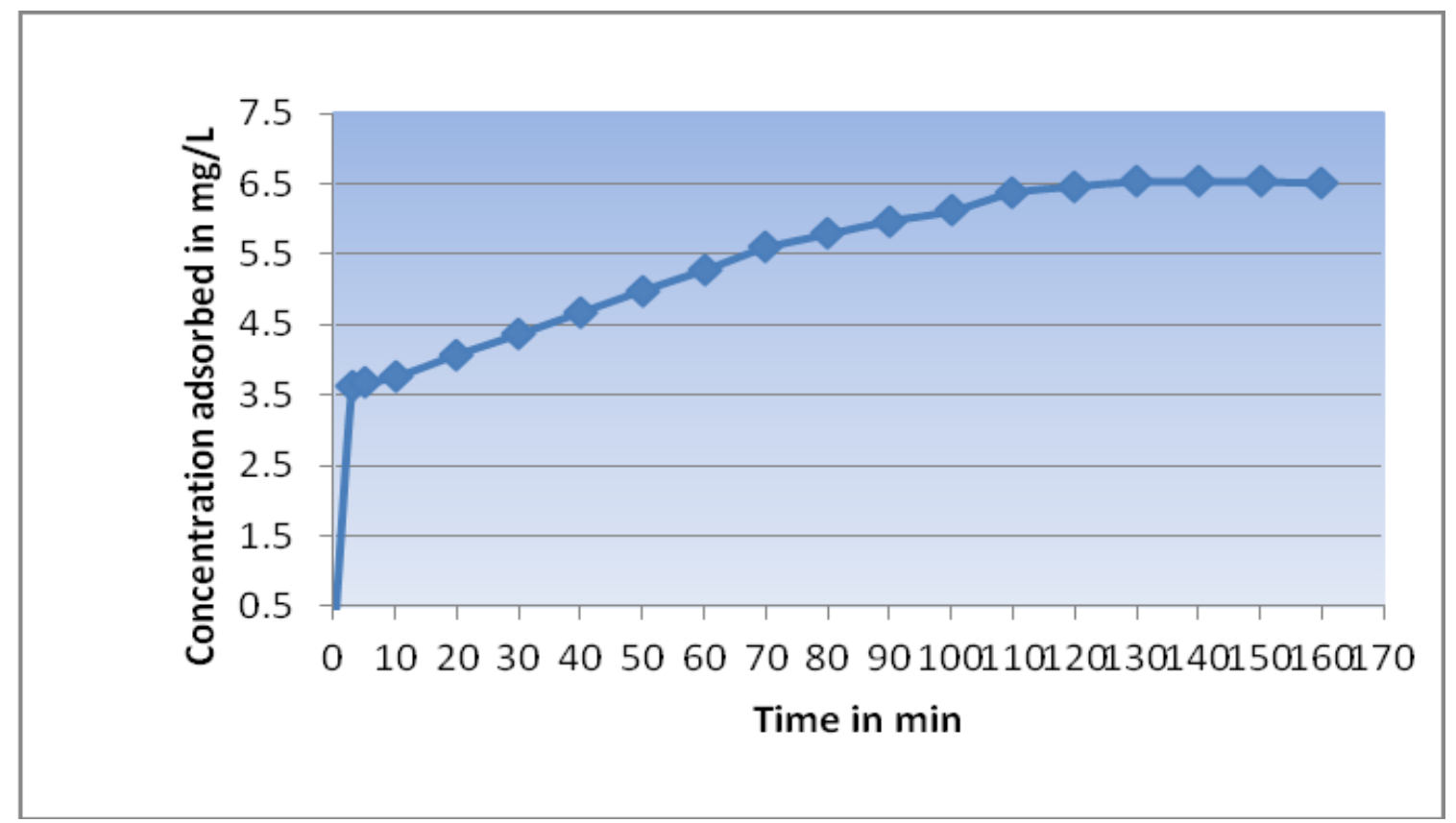

Figure 4. Effect of contact time of nitrate on laterite soil.

\section{1. 2. Effect of adsorbent dosage}

To determine the optimum dosage of adsorbent, adsorbents were added to the conical flask containing known concentration of Nitrate solution $(10 \mathrm{mg} / \mathrm{L})$. The solution in the conical flask was subjected to stirring for optimum contact time $(130 \mathrm{~min})$ and the dosage of 
laterite (adsorbent) varied from 200, 400, 600....2000 mg. After stirring the samples are filtered and analyzed for residual and removal of Nitrate concentration. The dosage which gives minimum residual concentration is chosen as optimum dosage, which is obtained at $1400 \mathrm{mg}$. The graph is plotted as shown in Fig. 5.

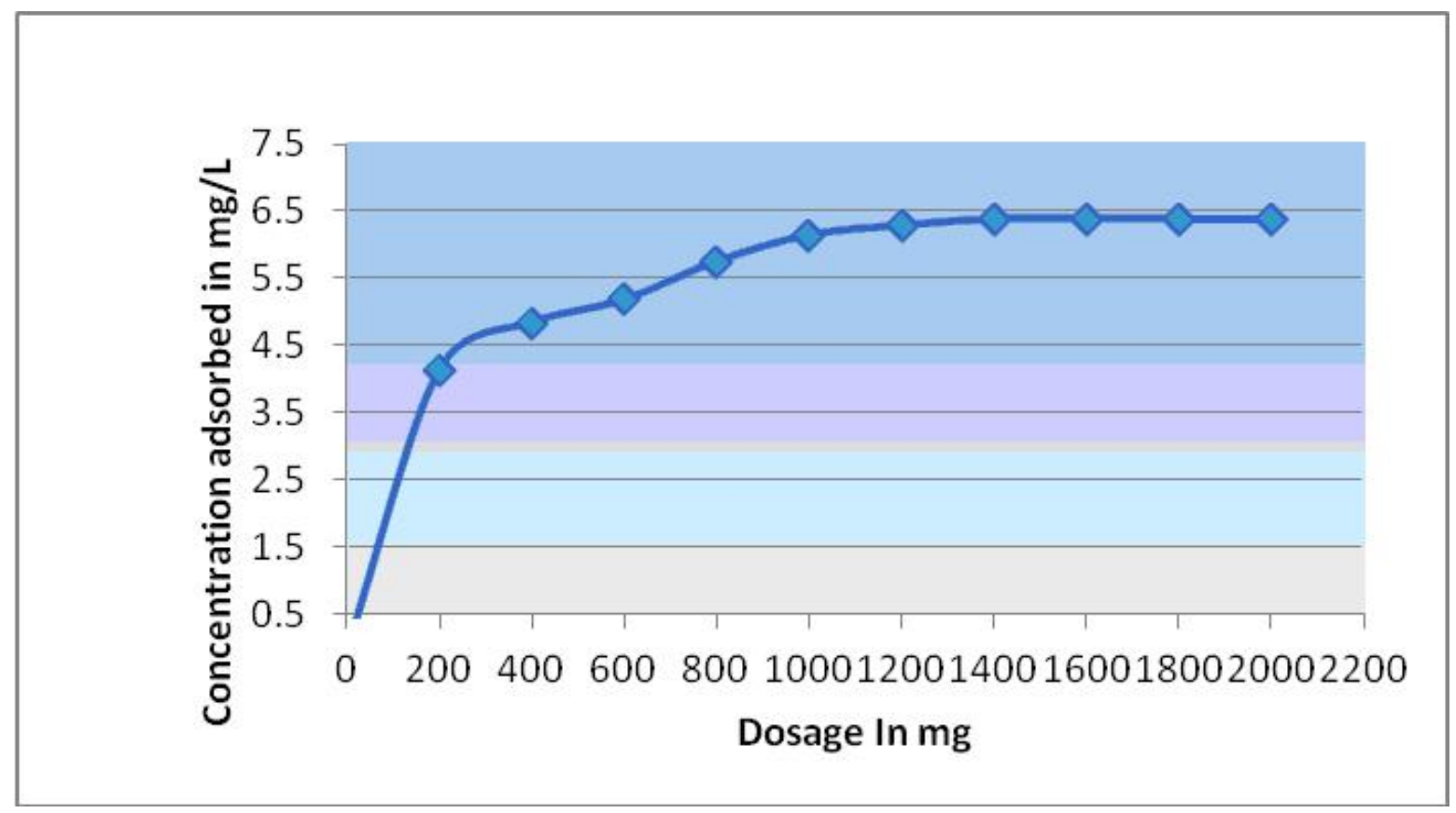

Figure 5. Effect of optimum dosage of nitrate on laterite soil.

\section{1. 3. Effect of $\mathrm{pH}$}

To determine the optimum $\mathrm{pH}$, series of conical flasks were taken with $100 \mathrm{ml}$ of 10 $\mathrm{mg} / \mathrm{L}$ Nitrate solution. Optimum dosage $(1400 \mathrm{mg})$ of soil is added, the $\mathrm{pH}$ of the flasks were adjusted ranging from 2.5 to 8.0. The flasks were shaken for optimum contact time (130 min). After stirring the samples are filtered and analyzed for the residual nitrate concentration. The flask which gives minimum residual concentration is selected as the optimum $\mathrm{pH}$, which is obtained at $\mathrm{pH}=6.0$ and the graph is plotted as shown in Fig. 6.

\section{2. Sorption Kinetics [9]}

The kinetics of nitrate removal was performed at constant temperature (i.e. $32 \pm 1{ }^{\circ} \mathrm{C}$ ) at different time interval of adsorption. The batch kinetic data for the adsorption of nitrate was tested for the first order reaction. The rate for the first order reaction is given by Levenspeil.

$$
\text { In } \mathrm{Ca} / \mathrm{Co}=\mathrm{kt}
$$

Or $2.303 \log [\mathrm{a} /(a-x)]=\mathrm{kt}$

Or $\log [\mathrm{a} /(a-x)]=\mathrm{kt} / 2.303$

Or k $=2.303 / \mathrm{t}\{\log [\mathrm{a} /(a-x)]\}$ 
Where, $\mathrm{x}=$ Amount of nitrate adsorbed at any time $\mathrm{t},(a-x)=$ Residual amount of nitrate $\& \mathrm{k}=$ Rate constant.

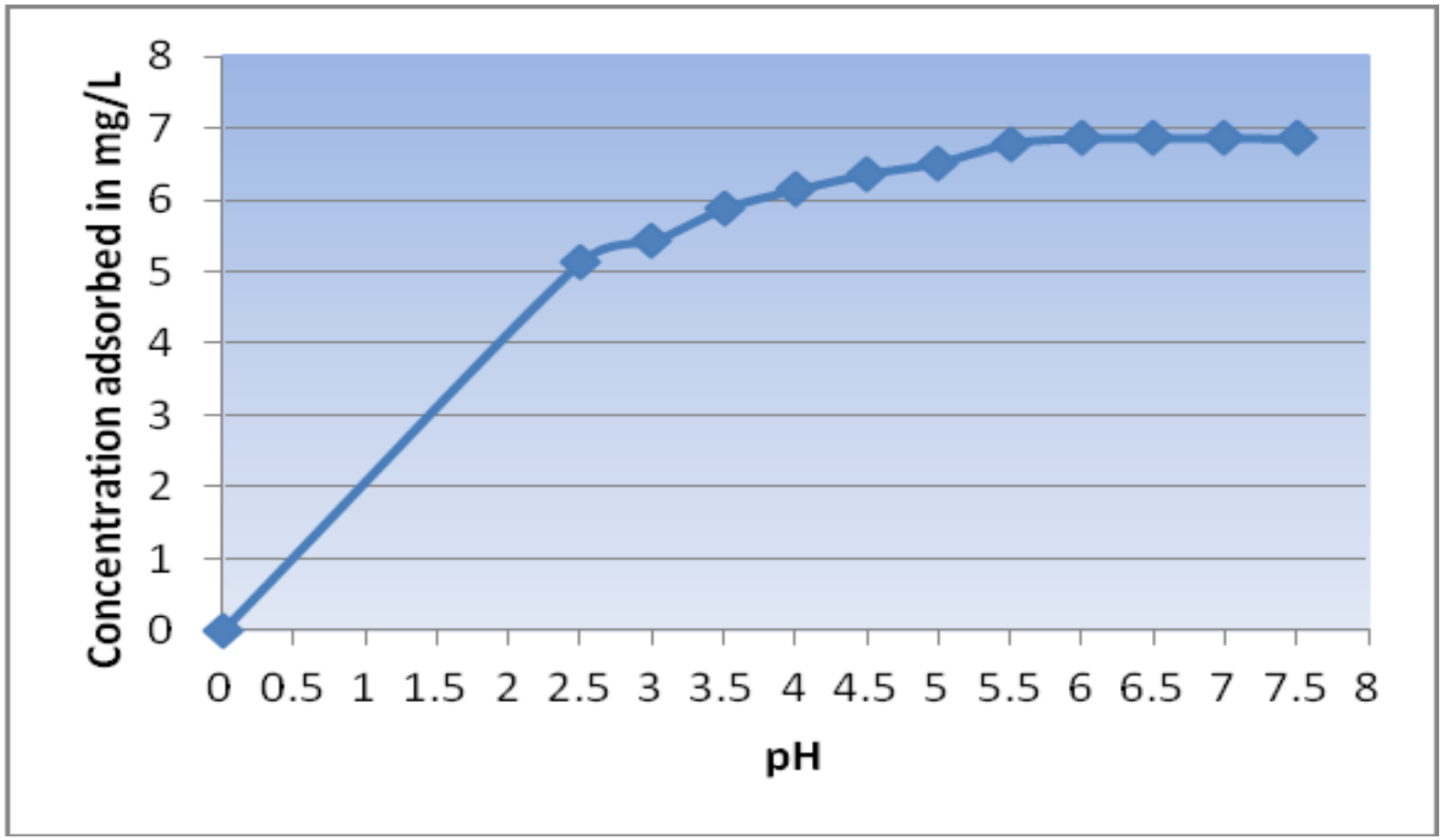

Figure 6. Effect of $\mathrm{pH}$ of nitrate on laterite soil.

The above equation (6) is of the type $\mathrm{y}=\mathrm{mx}$, Where, $\mathrm{y}=\log [\mathrm{a} /(a-x)]$, and $\mathrm{x}=\mathrm{t}$. This produces a straight line graph with slope $\mathrm{m}=\mathrm{k} / 2.303$. From the graph and calculated "k" values, it is observed that adsorption of nitrate follows first order rate equation. The resulting graph is as shown in the Fig. 7.

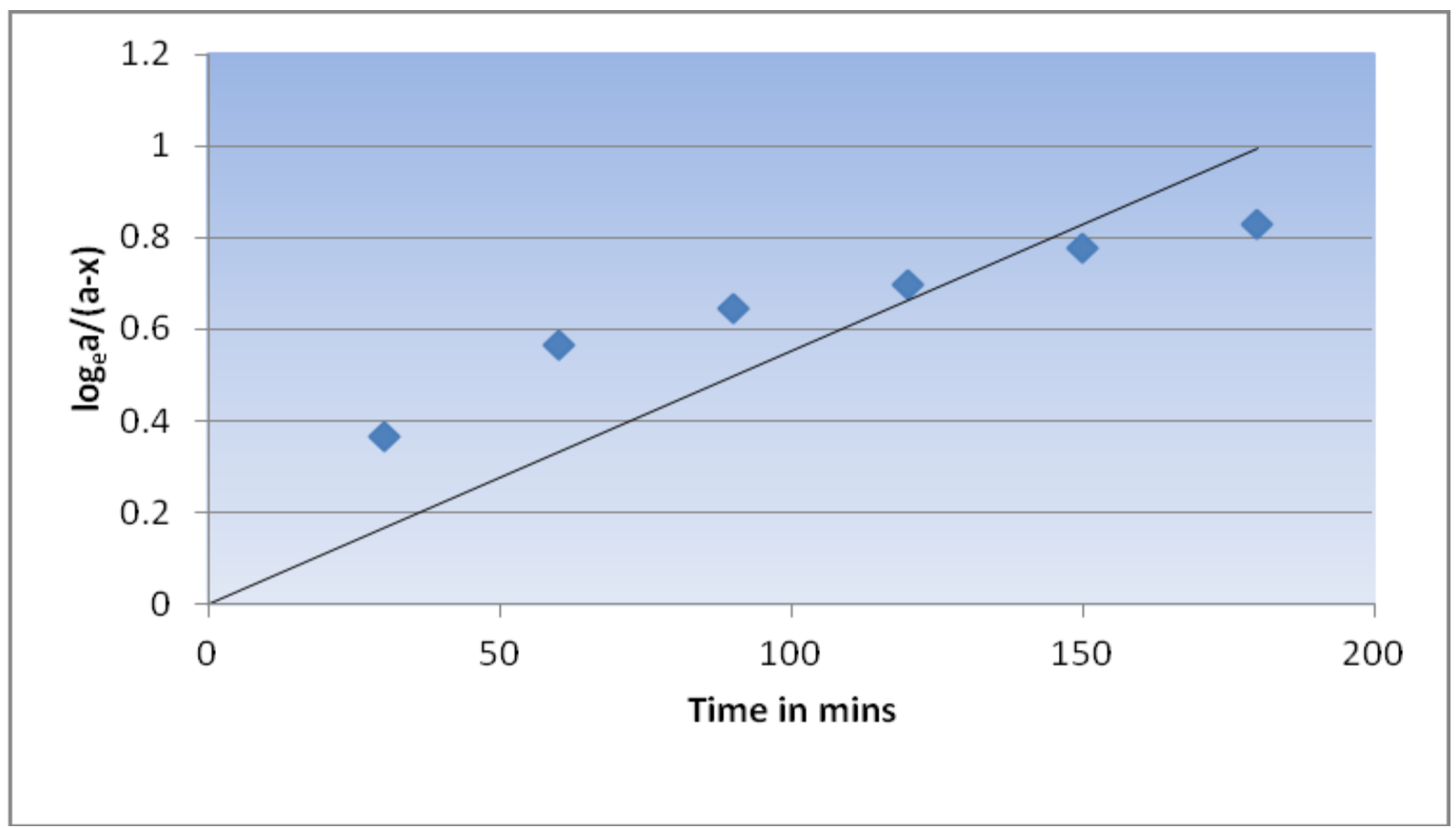

Figure 7. Reaction rate constant of nitrate adsorption by laterite soil. 


\section{3. Single Adsorption of Nitrate}

The batch experiments were carried out on laterite soil \& presented in Table 3, with concentrations of Nitrogen, 10, 15 and $20 \mathrm{mg} / \mathrm{L}$ respectively.

Table 3. Single adsorption of nitrate in laterite soil.

\begin{tabular}{|c|c|c|c|c|c|}
\hline $\mathbf{C}$ & $\mathbf{Q} \mathbf{~ m g / k g}$ & $\mathbf{1 / C}$ & $\mathbf{1} / \mathbf{Q}$ & $\log \mathbf{C}$ & $\log \mathbf{~}$ \\
$\mathbf{m g} / \mathbf{L}$ & {$[\mathbf{Q}=\mathbf{q}=(\mathbf{x} / \mathbf{m})]$} & $\mathbf{L} / \mathbf{m g}$ & $\mathbf{k g} / \mathbf{m g}$ & $\mathbf{m g} / \mathbf{L}$ & $\mathbf{m g} / \mathbf{L}$ \\
\hline 10 & 62.75 & 0.1 & 0.01556 & 1.0 & 1.8 \\
\hline 15 & 80.80 & 0.0666 & 0.01298 & 1.176 & 1.9 \\
\hline 20 & 117.6 & 0.04 & 0.00641 & 1.301 & 2.07 \\
\hline
\end{tabular}

The results of the nitrate test on laterite soil to fit the Langmuir isotherm were done, by plotting the results as shown in Fig. 8 and are fit to equation $(1 / \mathrm{Q})=0.029 *(1 / \mathrm{C})+0.0049$, where the regression coefficient $\mathrm{R}=0.998$. From the equation of fit, we obtained maximum adsorption and Langmuir constant, ' $\mathrm{a}$ ' $=62.5$. Separation factor $(\mathrm{R})$ is calculated by equation, $\mathrm{R}=1 /[(1+\mathrm{a}) \mathrm{Co}]=1 /[(1+62.5) 10]=0.00157$. Hence, $\mathrm{R}<1$ is favorable adsorption.

$$
\begin{gathered}
y=0.1576 x+0.0004 \\
R=0.998
\end{gathered}
$$

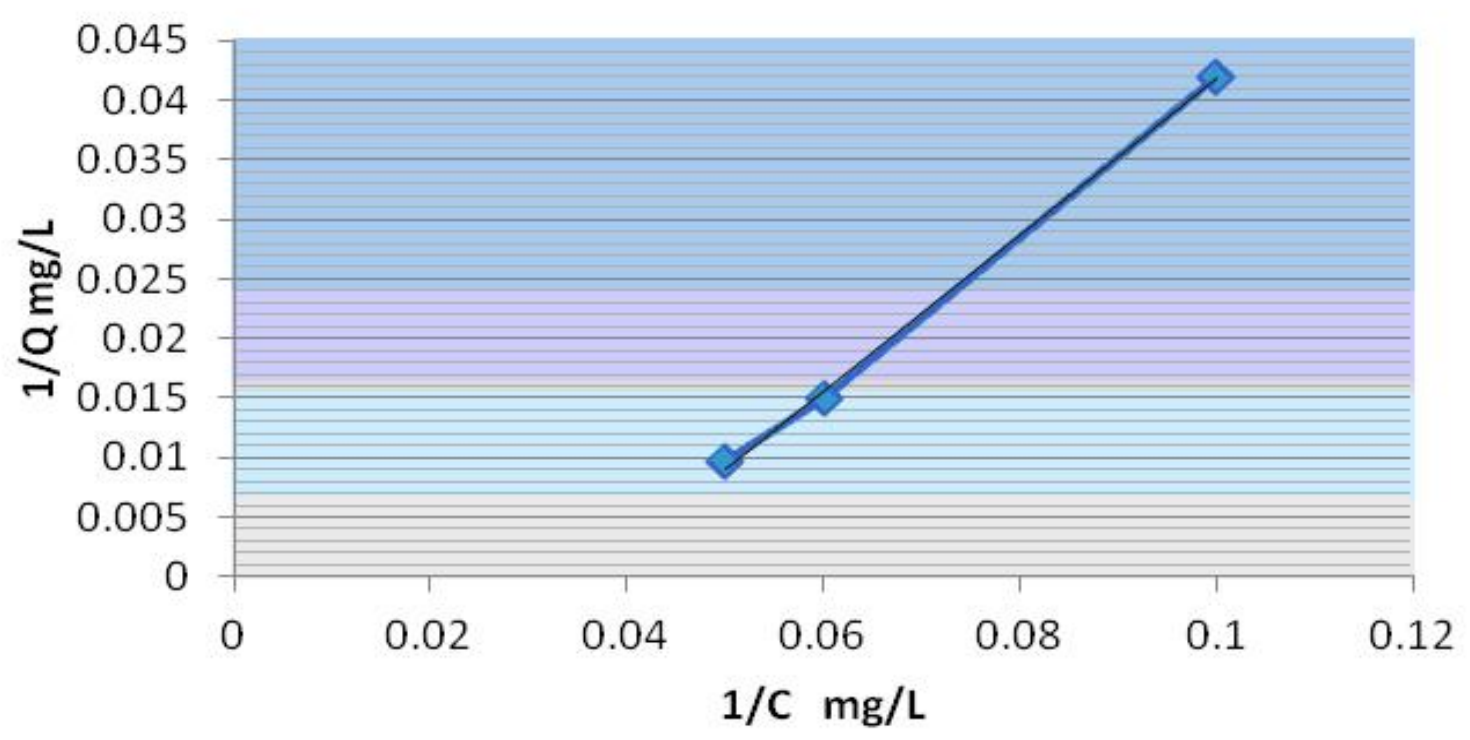

Figure 8. Single adsorption of nitrate on laterite soil (Langmuir Isotherm). 


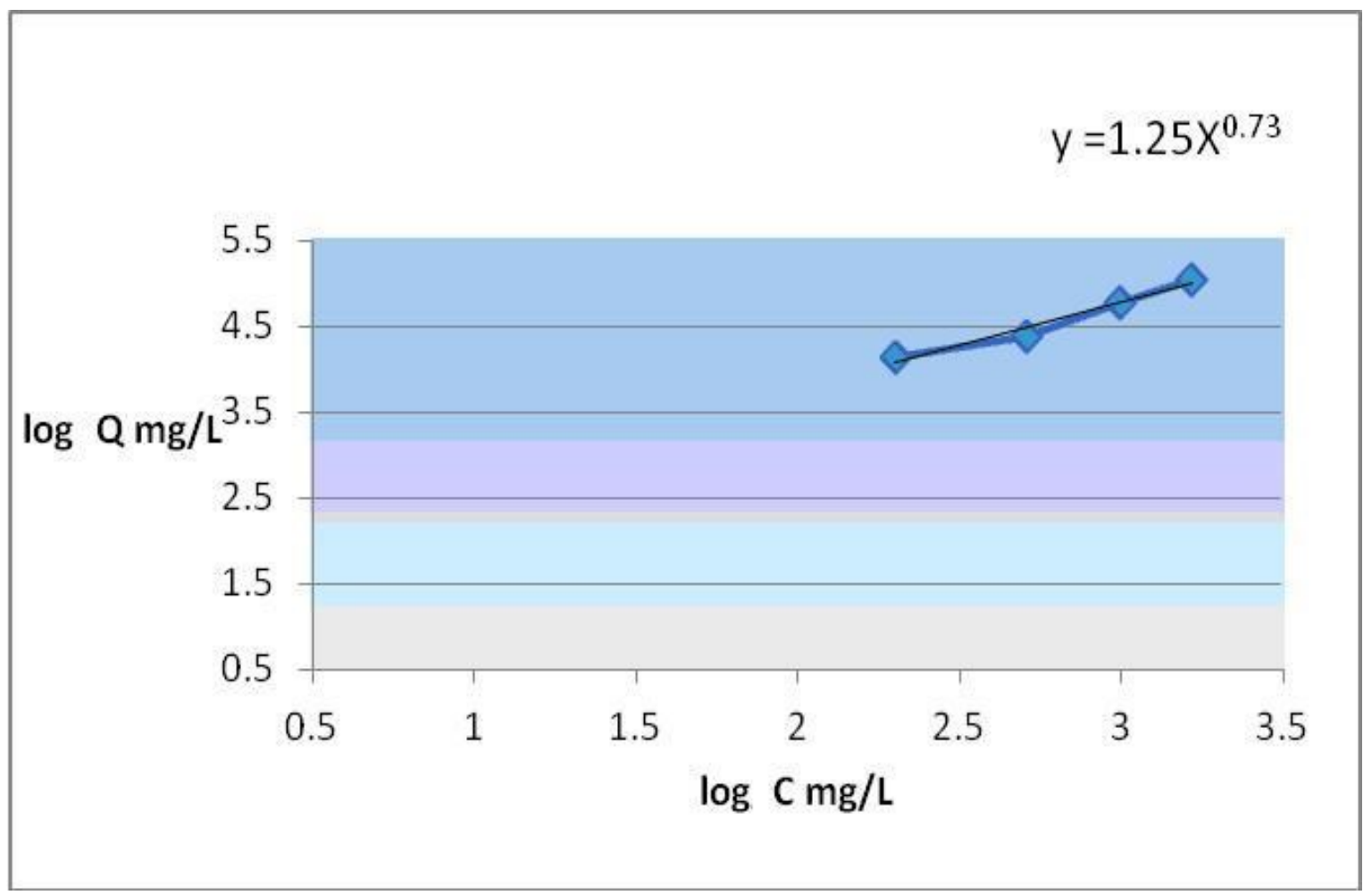

Figure 9. Single adsorption of nitrate on laterite soil (Freundlich Isotherm).

The same experimental results are fit to Freundlich isotherm and by equation $\log (\mathrm{x} / \mathrm{m})$ $=\log \mathrm{K}+(1 / \mathrm{n}) \log \mathrm{C}$, where $\log \mathrm{K}=0$ and we get $(1 / \mathrm{n})<1$. A plot of $\log \mathrm{Q}$ vs. $\log \mathrm{C}$ as shown in above Fig. 9 and fitting to the above equation, we obtain, $(1 / \mathrm{n})=0.769$ and $\mathrm{K}=10.7$. Where, $\mathrm{q}=(x / \mathrm{m})=$ Amount of solute adsorbed per unit mass of adsorbent in $\mathrm{mg} / \mathrm{kg}, \mathrm{C}=$ Equilibrium concentration of adsorbate in solution after adsorption in $\mathrm{mg} / \mathrm{L}, \mathrm{K}=$ Freundlich capacity factor and $(1 / \mathrm{n})=$ Freundlich intensity factor.

In this equation $(1 / n)<1$, therefore bond energies with surface density. We got $n=1.37$ and $\mathrm{n}>\mathbf{1}$ is favorable adsorption.

\section{CONCLUSION}

It is evident from the characteristic properties of laterite soil that is a good adsorbent for removing Nitrate and this adsorbent is easily and cheaply available. Kinetic study indicated that adsorption of Nitrate is very rapid up to 130 minutes and decrease while approaching equilibrium.

The rate of adsorption of Nitrate obeys first order rate equation. In batch experimental studies adsorption of Nitrate follows Freundlich and Langmuir isotherms indicating single adsorption of Nitrate and proves to be a favorable adsorption.

\section{ACKOWLEDGEMENTS}

Thanks to "Hyderabad Karnataka Education Society Gulbarga, Karnataka State, India". 


\section{References}

[1] M. Del Bubbaa, C. A. Ariasb, H. Brixc, Department of Plant Ecology, University of Aarhus, Nordlandsvej 68, Risskov DK-8240, March (2003) 96-101.

[2] Sardi \& Csatho1 et al, Studies on the phosphorous adsorption of different soil types of nutrient levels., 17th WCSS, Thailand, August (2002),14-21.

[3] A. Anderson, G. Siman, ACTA - Agriculture Scandinavica (1991) 45-49.

[4] Deutschd W. J., Groundwater geochemistry, fundamentals and applications to contamination, Lewis Publisher. New York. (1997) 47-55.

[5] Younger P. L., Banwart S. A., Hedin R. S., Mine Water: Hydrology, Pollution, Remediation, Kluwer Academic Publishers, Dordrecht (ISBN 1-4020-0137-1) (2002), 464.

[6] Quality Criteria for Water, U.S. Environmental Protection Agency, EPA\#440/5-86-001, (1986).

[7] Appelo C. A. J., Postma D., "Geochemistry, Groundwater and Pollution”. A. A. Balkema publishers, The Netherlands, (1996), 535.

[8] APHA (American Public Health Association) Standard method for examination of water wastewater specifications, NW, DC,(2003),6, $19^{\text {th }}$ edition.

[9] Padaki Srinvas Rao et.al, J. Environ. Sci. A27(8) (1992) 2227-2241.

[10] Webber T. N., Chakravarthi R. K., AICHE. J. 202 (1974) 228. 